\title{
Relationship between mucosal healing by tacrolimus and relapse of refractory ulcerative colitis: a retrospective study
}

\author{
Ayumi Ito* ${ }^{*}$, Syun Murasugi, Teppei Omori, Shinichi Nakamura and Katsutoshi Tokushige
}

\begin{abstract}
Background: Tacrolimus (TAC) is a powerful remission-inducing drug for refractory ulcerative colitis (UC). However, it is unclear whether mucosal healing $(\mathrm{MH})$ influences relapse after completion of TAC.We investigated whether $\mathrm{MH}$ is related to relapse after TAC.

Patients: Among 109 patients treated with TAC, 86 patients achieved clinical remission and 55 of them underwent colonoscopy at the end of TAC. These 55 patients were investigated.

Methods: Patients with MH at the end of TAC were classified into the MH group $(n=41)$, while patients without $\mathrm{MH}$ were classified into the non-MH group $(n=14)$. These groups were compared with respect to 1$)$ clinical characteristics before treatment, 2) clinical characteristics on completion of treatment, and 3) the relapse rate and adverse events rates. This is a retrospective study conducted at a single institution.

Results: 1) There was a significant difference in baseline age between the two groups before TAC therapy, but there were no significant differences in other clinical characteristics. The NMH group was younger (MH group: 48.1 (23-79) years, NMH group: 36.3 (18-58) years, $P=0.007$ ). Endoscopic scores showed significant differences between the 2 groups at the end of TAC. There were also significant differences in the steroid-free rate after 24 weeks ( $\mathrm{MH}$ group: $85.3 \%, \mathrm{NMH}$ group 50\%, $P=0.012$ ). There was no significant difference in the relapse rate between the 2 groups at 100 days after remission, but a significant difference was noted at 300 days (17\% vs. 43\%), 500 days (17\% vs. $75 \%$ ), and 1000 days ( $17 \%$ vs. $81 \%$ ) (all $P<0.05$ ).

Conclusions: TAC is effective for refractory ulcerative colitis. However, even if clinical remission is achieved, relapse is frequent when colonoscopy shows that $\mathrm{MH}$ has not been achieved. It is important to evaluate the mucosal response by colonoscopy on completion of TAC.
\end{abstract}

Keywords: Ulcerative colitis, Tacrolimus, Mucosal healing

\section{Background}

$\mathrm{UC}$ is a chronic benign intestinal disease. The prevalence of UC has increased worldwide and is expected to increase further [1]. Surgery may be indicated for severe UC, especially refractory prednisolone-resistant or prednisolone-dependent disease, which is often difficult

\footnotetext{
* Correspondence: ito.ayumi@twmu.ac.jp

Department of Gastroenterology, Tokyo Women's Medical University, Kawada-cho 8-1 Shinjuku-ku, Tokyo 162-8666, Japan
}

to treat medically. Nonresponse of UC to steroids leads to surgery $55-85 \%$ of the time [2]. However, surgery is associated with various complications $[3,4]$. TAC is used as remission induction therapy for refractory $\mathrm{UC}$, and the short-term remission rate achieved with TAC is high [5]. However, the relapse rate at 1 year after induction of remission by TAC is also high, in the range of 20 to $30 \%$ [6]. Prevention of relapse after remission has been achieved by TAC, which is an important issue in

(c) The Author(s). 2020 Open Access This article is licensed under a Creative Commons Attribution 4.0 International License, which permits use, sharing, adaptation, distribution and reproduction in any medium or format, as long as you give appropriate credit to the original author(s) and the source, provide a link to the Creative Commons licence, and indicate if changes were made. The images or other third party material in this article are included in the article's Creative Commons licence, unless indicated otherwise in a credit line to the material. If material is not included in the article's Creative Commons licence and your intended use is not permitted by statutory regulation or exceeds the permitted use, you will need to obtain permission directly from the copyright holder. To view a copy of this licence, visit http://creativecommons.org/licenses/by/4.0/ The Creative Commons Public Domain Dedication waiver (http://creativecommons.org/publicdomain/zero/1.0/) applies to the data made available in this article, unless otherwise stated in a credit line to the data. 
patients with refractory UC. Reports have recently been published concerning the control of UC relapse by achieving $\mathrm{MH}$ [7], but it has not been clarified whether $\mathrm{MH}$ influences relapse after TAC therapy. Therefore, this study was performed to investigate the relationship between $\mathrm{MH}$ and relapse of UC after TAC.

\section{Methods}

At our department, TAC was administered to 109 patients from April 2016 to December 2018 (mean followup period: $819 \pm 781$ days). TAC was given at 0.025 to $0.075 \mathrm{mg} / \mathrm{kg}$ body weight twice daily before breakfast and dinner. Blood samples were collected daily for measurement of TAC levels until the target blood concentration was reached. The TAC dose was adjusted to reach the target trough concentration of 10 to $15 \mathrm{ng} / \mathrm{mL}$ blood within two weeks of starting TAC remission induction therapy.

Then, 2 to 3 weeks after the TAC concentration was within the target range, the dose was adjusted again to reach a new lower target concentration of 5 to $10 \mathrm{ng} / \mathrm{mL}$.

Clinical remission was achieved in 86 patients. Colonoscopy was performed at the end of TAC therapy in 55 patients who had agreed to receive colonoscopy (Fig. 1). All patients received steroids before TAC. PSL was administered to all 55 patients before initiation of TAC, so all patients had prednisolone-dependent or prednisoloneresistant refractory UC. Prior to TAC, 5 patients had used biologics.
Endoscopic evaluation was performed to determine the Mayo score and the UCEIS score [8, 9]. Before steroid administration, 42 patients underwent endoscopy (MH group: $n=33$, NMH group: $n=9$ ). MH was defined as a Mayo score of 0 or 1 [7]. Patients who achieved $\mathrm{MH}$ at the end of TAC were classified into the $\mathrm{MH}$ group (group: $n=41$ ), while patients who did not were classified into the non-MH group (group: $n=14$ ). The Lichtiger score was determined as the clinical activity index (CAI) [10]. The $\mathrm{MH}$ and NMH groups were compared with respect to the following three factors: 1) clinical characteristics before PSL, CAI, hemoglobin, albumin, CRP (C-reactive protein), endoscopic scores (Mayo and UCEIS) and TAC (sex, age, duration of UC, site of UC, PSL responsiveness (dependent/resistant), CAI, hemoglobin, albumin, CRP, endoscopic scores (Mayo and UCEIS), and time to reach the target trough level of $\mathrm{TAC}) ; 2$ ) clinical characteristics at the end of TAC (CAI, hemoglobin, albumin, CRP, endoscopic scores (Mayo and UCEIS), total PSL dose during hospitalization, duration of TAC, frequency of combined azathioprine (AZA) therapy, and steroid-free rate after 24 weeks), and 3) the relapse rate at 100 ( $\mathrm{MH}$ group: $n=39, \mathrm{NMH}$ group: $n=15$ ), 300 (MH group: $n=35$, NMH group: $n=$ 11), 500 (MH group: $n=32$, NMH group: $n=3$ ), and 1000 days (MH group: $n=16$, NMH group: $n=3$ ) after achieving remission. Remission was defined as a CAI $\leq 4$ at 4 weeks or longer after initiation of remission induction therapy. The total PSL dose during hospitalization was the amount of PSL used until a clinical remission and discharge. Surgery was not required as a result of

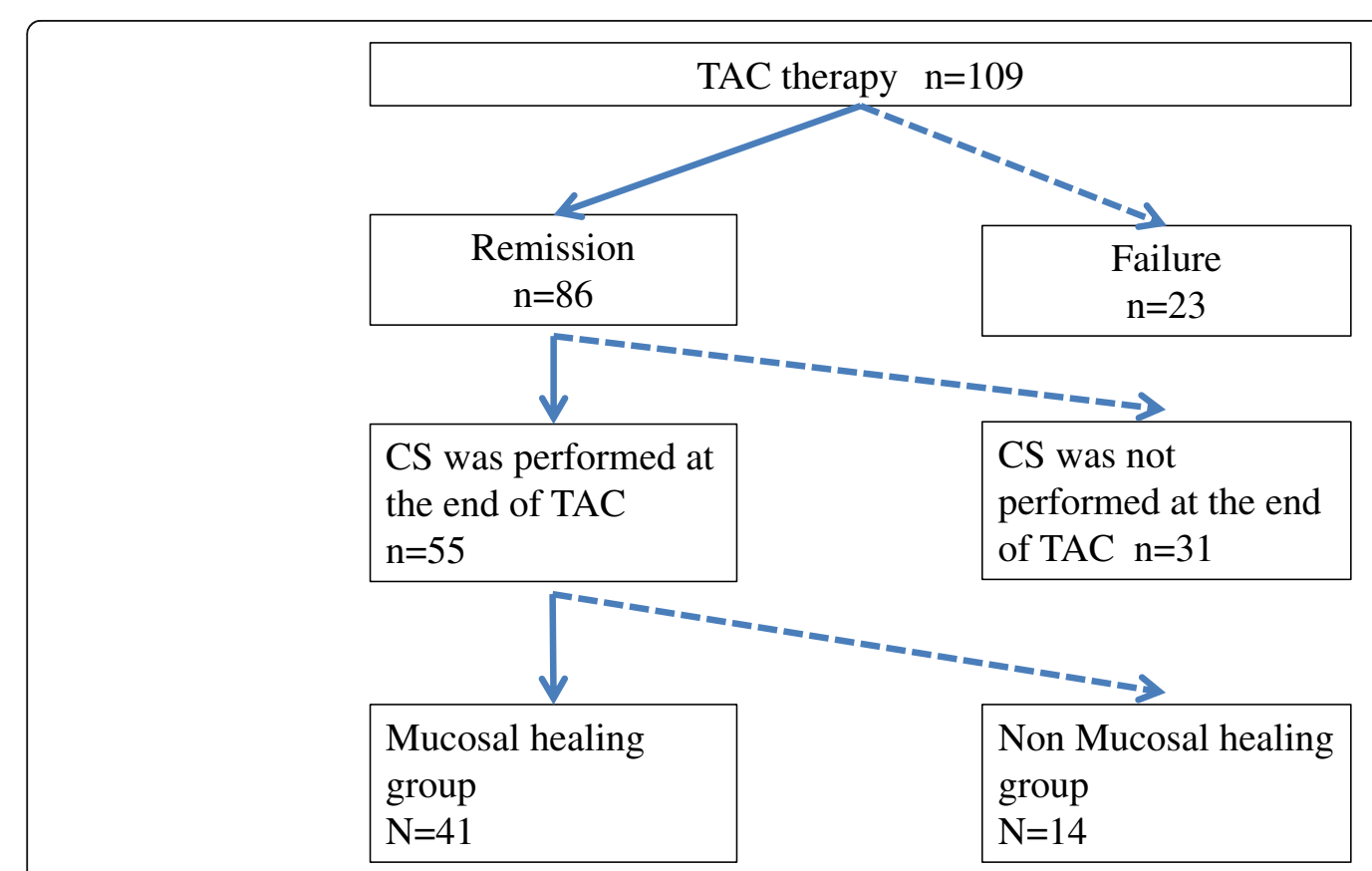

Fig. 1 Outline of the mucosal healing group and nonmucosal healing group 
induction. Relapse was defined as the need for high-dose intravenous steroid therapy, switching to a biologic, readministration of TAC, or re-administration of TAC at a higher dose (target trough level $\geq 10 \mathrm{ng} / \mathrm{dL}$ ) to induce remission again.

Adverse events were defined as any undesired or unintended illness or signs thereof (including abnormal laboratory values) occurring in subjects receiving TAC.

\section{Statistical analysis}

The results are expressed as the number of patients or as the mean \pm standard deviation. The Wilcoxon test was used for comparisons between the 2 groups, and differences were considered to be significant at $P<0.05$. JMP Pro12 (Statistical Discover, SAS) was used for all analyses.

\section{Results}

\section{Clinical characteristics}

The clinical characteristics of the MH and NMH groups are summarized in Table 1.

Before PSL administration, there was no significant difference between the two groups in CAI MH group: 13.3 (9-19), NMH group: 13.1 (10-17), $P=0.493$, hemoglobin MH group: 11 (7.5-12.9), NMH group: $12.6(7.9-15.1) \mathrm{g} /$ $\mathrm{dL}, P=0.19$, albumin $\mathrm{MH}$ group: 3.4 (1.9-4.4), NMH group: $3.4(2-4.6) \mathrm{g} / \mathrm{dL}, P=0.889$, CRP $\mathrm{MH}$ group: 3.9 (0.2-22.6), NMH group: $2.9(0.04-11.9) \mathrm{mg} / \mathrm{dL}, P=0.636$, or either endoscopic score (Mayo: MH group: $2.9(2,3)$,
NMH group: 3 (3), $P=0.341$; UCEIS MH group: 6.6 (48), NMH group: 7.4 (6-8), $P=0.236)$ (Table 1).

The age at initiation of treatment showed a significant difference between the 2 groups ( $\mathrm{MH}$ group: 48.1 (2379) years, NMH group: $36.3(18-58)$ years, $P=0.007)$, but there were no significant differences of other factors (sex M/F MH group: 20/21, NMH group: $9 / 5, P=0.396$; duration of $\mathrm{UC} \mathrm{MH}$ group: 9.4 (0-33) years, $\mathrm{NMH}$ group: $9.0(0-26)$ years, $P=0.88$; site of UC left colon/ total colon $\mathrm{MH}$ group: $25 / 16$, NMH group: $8 / 6, P=0.8$; steroid responsiveness (dependent/resistant) $\mathrm{MH}$ group: 18/23, NMH group: 6/8, $P=0.889$; CAI: $\mathrm{MH}$ group: 12.9 (7-19), NMH group: $13.4 \quad(11-17), \quad P=0.593$; hemoglobin $\mathrm{MH}$ group: 12 (7.5-14.9), NMH group: 12.9 (8.1-15.1) g/dL, $P=0.191$; albumin $\mathrm{MH}$ group: 3.3 (1.74.4), NMH group: 3.3 (2-4.6) g/dL, $P=0.838$; CRP MH group: 3.5 (0.04-24.1), NMH group: 2.6 (0.04-10.4) mg/ $\mathrm{dL}, P=0.525$; endoscopic scores Mayo: $\mathrm{MH}$ group: 2.9 $(2,3)$, NMH group: 3 (3), $P=0.306$; UCEIS MH group: 6.7 (4-8), NMH group: 7.2 (6-8), $P=0.136)$; and time to achieve the target trough level of TAC MH group: 3.1 (1-10), NMH group: $4.5(1-9)$ days, $P=0.07)$ (Table 1$)$.

\section{Clinical characteristics on completion of TAC}

At the end of TAC, significant differences in the endoscopic scores were noted between the 2 groups (Mayo score $\mathrm{MH}$ group: $0.6(0-1), \mathrm{NMH}$ group: $2.2(2,3)$; UCEIS score MH group: $1.1(0-4)$, NMH group: 4.4 (4, 5), both $P=0.001)$. There was also a significant

Table 1 Comparision between the mucosal healing group (MH Group) and non-mucosal healing group (NMH Group) before treatment

\begin{tabular}{|c|c|c|c|}
\hline & $\begin{array}{l}\text { MH Group } \\
n=41\end{array}$ & $\begin{array}{l}\text { NMH Group } \\
n=14\end{array}$ & $p$-value \\
\hline \multicolumn{4}{|l|}{ Data before PSL administration } \\
\hline $\mathrm{CAl}$ & $13.3(9-19)$ & $13.1(10-17)$ & 0.493 \\
\hline $\mathrm{Hb}(\mathrm{g} / \mathrm{dl})$ & $11(7.5-12.9)$ & $12.6(7.9-15.1)$ & 0.19 \\
\hline Alb (g/dl) & $3.4(1.9-4.4)$ & $3.4(2-4.6)$ & 0.889 \\
\hline CRP (mg/dl) & $3.9(0.2-22.6)$ & $2.9(0.04-11.9)$ & 0.636 \\
\hline Mayo score ${ }^{a}$ & $2.9(2-3)$ & $3(3)$ & 0.341 \\
\hline UCEIS score ${ }^{a}$ & $6.6(4-8)$ & $7.4(6-8)$ & 0.236 \\
\hline \multicolumn{4}{|l|}{ Data before TAC administration } \\
\hline CAl & $12.9(7-19)$ & $13.4(11-17)$ & 0.593 \\
\hline $\mathrm{Hb}(\mathrm{g} / \mathrm{dl})$ & $12(7.5-14.9)$ & $12.9(8.1-15.1)$ & 0.191 \\
\hline Alb $(g / d l)$ & $3.3(1.7-4.4)$ & $3.3(2-4.6)$ & 0.838 \\
\hline CRP (mg/dl) & $3.5(0.04-24.1)$ & $2.6(0.04-10.4)$ & 0.525 \\
\hline Mayo score & $2.9(2-3)$ & $3(3)$ & 0.306 \\
\hline UCEIS score & $6.7(4-8)$ & $7.2(6-8)$ & 0.136 \\
\hline Time to achieve the target TAC trough level (days) & $3.1(1-10)$ & $4.5(1-9)$ & 0.07 \\
\hline
\end{tabular}


difference in the duration of TAC (MH group: 297.6 (58922) days, NMH group: $136.9(70-373)$ days, $P=0.014)$ and the steroid-free rate after 24 weeks (MH group: $85.3 \%$, $\mathrm{NMH}$ group $50 \%, P=0.012$ ). However, there were no significant differences between the 2 groups with regard to CAI (MH group: 2.8 (1-4), NMH group: $2.7(1-4), P=$ 0.741 ), hemoglobin ( $\mathrm{MH}$ group: 11.7 (9.6-15.6), $\mathrm{NMH}$ group: $13.2(11-15.8) \mathrm{g} / \mathrm{dL}, P=0.098)$, albumin $(\mathrm{MH}$ group: 3.8 (3-4.7), NMH group: $3.8(2.9-4.6) \mathrm{g} / \mathrm{dL}, P=$ 0.703), CRP (MH group: 0.12 (0.04-1.15), NMH group: $0.15(0.03-1.03) \mathrm{mg} / \mathrm{dL}, P=0.665)$, total dose of PSL up to remission MH group: 685 (330-1690), NMH group: 755 (335-1322) mg, $P=0.501$ ), or use of AZA (MH group: $34 /$ 7, NMH group: $11 / 3, P=0.715$ ) (Table 2 ).

\section{Relapse rate}

The relapse rate at 100 days after induction of remission showed no significant difference between the $\mathrm{MH}$ and $\mathrm{NMH}$ groups, being $8 \%$ in both groups. However, there was a significant difference in the relapse rate between the 2 groups at 300 days (MH group: 17\%, NMH group: 43\%), 500 days (MH group: 17\%, NMH group: 75\%), and 1000 days (MH group: 17\%, NMH group: $81 \%$ ) after induction of remission $(P<0.05)$ (Fig. 3, Table 3). Adverse events related to TAC were reported as tremor, renal impairment, headache, and hypomagnesemia in 7, 5, 3, and 3 patients, respectively (Table 4). The prevalence of adverse events was not different between the $\mathrm{MH}$ and $\mathrm{NMH}$ groups.

In no patient was TAC discontinued due to adverse events.

\section{Discussion}

\section{Clinical characteristics}

$\mathrm{UC}$ is a chronic inflammatory disease that repeats episodes of relapse and remission.Only $20-30 \%$ of patients with UC moderate or more relapse have difficulty in treatment. PSL are used first in moderate or more severe cases [2]. The patients in this study also had moderate or worse UC. The clinical activity index (CAI) before PSL administration was high, and the endoscopy score (Mayo, UCEIS) was high in 42 patients who underwent endoscopy (Table 1). Therefore, PSL was given before TAC in all cases that were steroid-resistant or refractory. PSL is one of the poor prognostic factors for UC. In cases where PSL must be used, repeated relapses require surgery [11]. Therefore, PSL use has been reported to be one of the markers of UC severity. For intractable cases, it is important to prevent relapse after induction and maintain remission.

Various reports have been published on the benefits of achieving $\mathrm{MH}$ and this is considered a therapeutic goal for $\mathrm{UC}$, as $\mathrm{MH}$ has reduced the rate of relapse $[7,12]$.

TAC is used to induce the remission of UC. However, the duration of treatment with TAC is not clearly defined in the ECCO Guidelines [2]. In this study, we compared patients treated with TAC who achieved mucosal healing ( $\mathrm{MH}$ group) or did not achieve mucosal healing (NMH group). Among the clinical characteristics that we investigated, the age at initiation of treatment was significantly lower in the NMH group. In this study, TAC was started at the time of hospital admission and was completed during outpatient follow-up, so oral administration of TAC was managed by the patients themselves after discharge from the hospital. The percentage of young people in the NMH group was high. This may have contributed to reduced oral drug compliance.

It has been reported that compliance with internal medicine is likely to be reduced among young people [13]. TAC blood levels are affected by diet. Therefore, the time for internal use must be adjusted twice a day.

$\frac{\text { Table } 2 \text { Comparision between mucosal healing group (MH Group) and non-mucosal healing group (NMH Group) at the end of TAC }}{\text { NMH Group }}$

\begin{tabular}{|c|c|}
\hline $\begin{array}{l}\text { MH Group } \\
n=41\end{array}$ & $\begin{array}{l}\text { NMH Group } \\
n=14\end{array}$ \\
\hline
\end{tabular}

TAC at the end of data

$\begin{array}{llll}\text { CAl } & 2.8(1-4) & 2.7(1-4) & 0.741 \\ \mathrm{Hb}(\mathrm{g} / \mathrm{dl}) & 11.7(9.6-15.6) & 13.2(11-15.8) & 0.098 \\ \mathrm{Alb}(\mathrm{g} / \mathrm{dl}) & 3.8(3-4.7) & 3.8(2.9-4.6) & 0.703 \\ \mathrm{CRP}(\mathrm{mg} / \mathrm{dl}) & 0.12(0.04-1.15) & 0.15(0.03-1.03) & 0.665 \\ \text { Mayo score } & 0.63(0-1) & 2.21(2-3) & 0.001 \\ \text { UCEIS score } & 1.19(0-4) & 4.42(4-5) & 0.001 \\ \text { Total prednisolone dose during hospitalization }(\mathrm{mg}) & 685(330-1690) & 755(335-1322) & 0.501 \\ \text { Duration of TAC (days) } & 297.6(58-922) & 136.9(70-373) & 0.014 \\ \text { Combined use of AZA (yes / no) } & 34 / 7 & 11 / 3 & 0.715 \\ \text { Steroid free rate at 24 weeks } & 35(85.3 \%) & 7(50 \%) & 0.012 \\ \text { n (\%) } & & \end{array}$

n (\%)

Data are expressed as the mean \pm standard deviation or the number of patients 
Table 3 Relapse rate

\begin{tabular}{llll}
\hline & MH Group & NMH Group & $p$-value \\
\hline Relapse rate after 100 days (\%) & 8 & 8 & N.S. \\
Relapse rate after 300 days (\%) & 17 & 43 & $P<0.05$ \\
Relapse rate after 500 days (\%) & 17 & 75 & $P<0.05$ \\
Relapse rate after 1000 days (\%) & 17 & 80 & $P<0.05$ \\
\hline
\end{tabular}

Compliance with oral administration will decline when oral administration becomes more complex due to other drugs [14]. However, this study did not confirm compliance with internal medicine after discharge and did not measure frequent blood troughs.

Therefore, the decline in compliance with oral administration of young people is only speculation. Furthermore, as the clinical symptoms improve, the compliance with oral administration tends to be further reduced [15]. Therefore, it can be suggested that compliance of younger patients decreases after discharge from the hospital, resulting in failure to achieve $\mathrm{MH}$. Other clinical characteristics, particularly the duration of UC, CAI, and endoscopic severity scores before initiation of TAC, were not correlated with $\mathrm{MH}$.

\section{Clinical characteristics on completion of TAC}

Comparison of clinical characteristics between the $\mathrm{MH}$ and NMH groups at the end of TAC revealed no significant differences in CAI, hemoglobin, albumin, or CRP. At the end of treatment, detailed data about clinical characteristics and laboratory parameters were obtained from both groups. However, there were no significant differences in clinical or laboratory characteristics between the 2 groups, suggesting that it is difficult to predict the achievement of $\mathrm{MH}$ based on these factors. By definition, there were significant differences in endoscopic findings between the $\mathrm{MH}$ and $\mathrm{NMH}$ groups (Table 2, Fig. 2). Importantly, the duration of TAC was markedly different between the $\mathrm{MH}$ and NMH groups, being significantly longer in the $\mathrm{MH}$ group (Table 2).

There are no rules regarding the duration of TAC administration. Therefore, the duration of TAC administration varied from physician to attendant, resulting in a variable duration of administration.

Table 4 Adverse events from TAC usage

\begin{tabular}{lll}
\hline & $\begin{array}{l}\text { MH Group } \\
n=41\end{array}$ & $\begin{array}{l}\text { NMH Group } \\
n=14\end{array}$ \\
\hline Tremors & $5(12.1 \%)$ & $2(14.2 \%)$ \\
Nephropathy & $4(9.7 \%)$ & $1(7.1 \%)$ \\
Headache & $1(2.4 \%)$ & $2(14.2 \%)$ \\
hypomagnesemia & $2(4.8 \%)$ & $1(7.1 \%)$ \\
\hline
\end{tabular}

Data are expressed as the number of patients (percentage)
This suggests the possibility that $\mathrm{MH}$ is more likely to be obtained by long-term treatment with TAC. Therefore, it may be necessary to continue TAC after clinical remission if $\mathrm{MH}$ has not been achieved. There was no significant difference in the combination of AZA between the $\mathrm{MH}$ group and $\mathrm{NMH}$ group. Therefore, whether AZA contributed to the promotion of $\mathrm{MH}$ was unclear in this study. The steroid-free rate at 24 weeks showed a significant difference between the 2 groups. PSL are generally the first-line treatment for moderate/ severe UC $[2,16]$. If there is no response to PSL, switching therapy or the addition of other drugs is required. When a response is noted, the PSL dosage should be tapered or discontinued as soon as possible because these drugs have no remission-maintaining effect and prolonged use may cause steroid dependence, leading to intractability of UC $[2,16-18,19]$. In this study, TAC was not used in the NMH group for long enough. Therefore, $\mathrm{MH}$ could not be achieved in the NMH group, and steroid-free treatment could not be achieved. TAC must be used for a sufficient period to be steroid free.

Prolonged use of steroids may also cause a wide variety of adverse events [18]. Accordingly, achievement of a steroid-free status in UC patients is important to prevent intractability of the disease and steroid-related adverse events $[2,20]$.

\section{Relapse rate}

At 100 days after induction of remission, the relapse rate was the same in the $\mathrm{MH}$ and $\mathrm{NMH}$ groups ( $\mathrm{MH}$ group: $8 \%$, NMH group: $8 \%$ ), but the relapse rate showed a significant difference between the two groups at 300 days ( $\mathrm{MH}$ group: $17 \%$, NMH group: $43 \%$ ), 500 days (MH group: $17 \%$, $\mathrm{NMH}$ group: $75 \%$ ), and 1000 days (MH group: 17\%, $\mathrm{NMH}$ group: $81 \%)(P<0.05)$ (Fig. 3, Table 3). That is the relapse rate was lower from 300 days on in the $\mathrm{MH}$ group. It has been reported that $\mathrm{MH}$ affects the recurrence and maintenance of remission [11]. Achieving $\mathrm{MH}$ in infliximab studies has been reported to contribute to the maintenance of remission. Achieving $\mathrm{MH}$ is considered to be a target for $\mathrm{UC}$ treatment. This study focused on achieving $\mathrm{MH}$ with TAC [12]. Unlikely previous reports, we focused on the achievement of MH by TAC in this study.

There are few reports examining the relationship with $\mathrm{MH}$ in refractory cases using TAC. Miyoshi et al. reported that colonoscopy results 3 months after TAC were associated with later relapse [21]. This study also reports that $\mathrm{MH}$ was involved in maintaining remission. However, our study differs from Miyoshi's report in the period of use of TAC. TAC was used until MH was achieved to prevent relapse.

The importance of preventing relapse differs between patients with refractory or moderate/severe UC and patients with mild UC. Refractory or relapsing moderate/ 


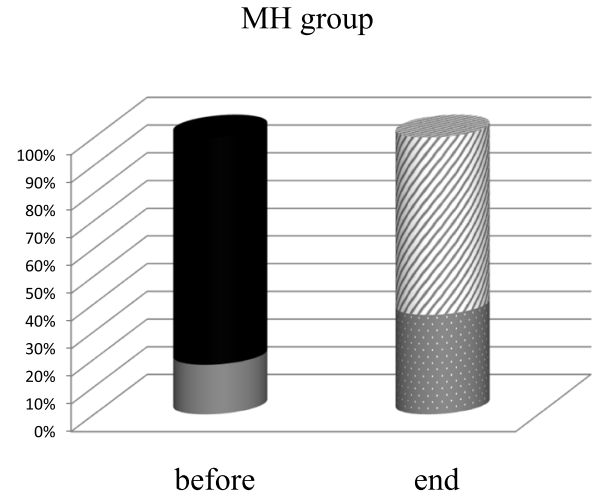

Duration of tacrolimus therapy (days) $\mathrm{MH}: 295 \pm 261$

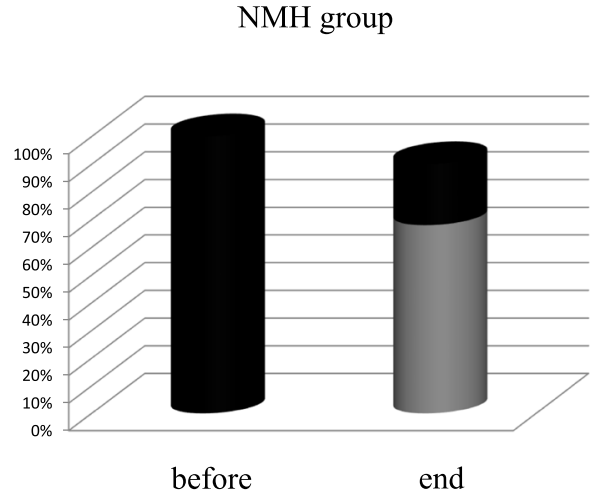

Duration of tacrolimus therapy (days) MH: $126 \pm 81$

Fig. 2 Changes in the endoscopic findings of the $\mathrm{MH}$ group and $\mathrm{NMH}$ group

severe UC results in frequent hospital attendance, admission, and intensified drug therapy, which have a detrimental impact on the quality of life [22, 23].

Furthermore, surgery is often required to manage patients with refractory or relapsing moderate/severe UC [4]. Therefore, maintenance of remission is very important for refractory or relapsing moderate/severe UC.

As adverse events related to TAC therapy, tremor (7 patients), renal impairment (5 patients), headache (3 patients), and hypomagnesemia ( 3 patients) were observed in the present study (Table 4). All of these events improved after dosage reduction of TAC. Renal impairment was improved by the addition of fluids and TAC could be continued [24, 25].

A strength of this paper is that the total amount of PSL until remission (mg), the number of days until the
TAC trough was achieved (day), and the TAC administration period are examined. There were several reports on TAC and MH. However, there is no report on these points. This suggests that this report may serve as a standard for treatment in clinical practice.

Unfortunately, this study did not use calprotectin to assess MH. It has been reported that calprotectin is simple and is an excellent biomarker for predicting $\mathrm{MH}$ and relapse. In the future, it is necessary to consider additional factors such as this [26].

The limitations of this study included its retrospective design and its collection of data from a single center, which could have resulted in bias. To confirm our findings, it will be necessary to perform a prospective multicenter study in a larger number of patients.

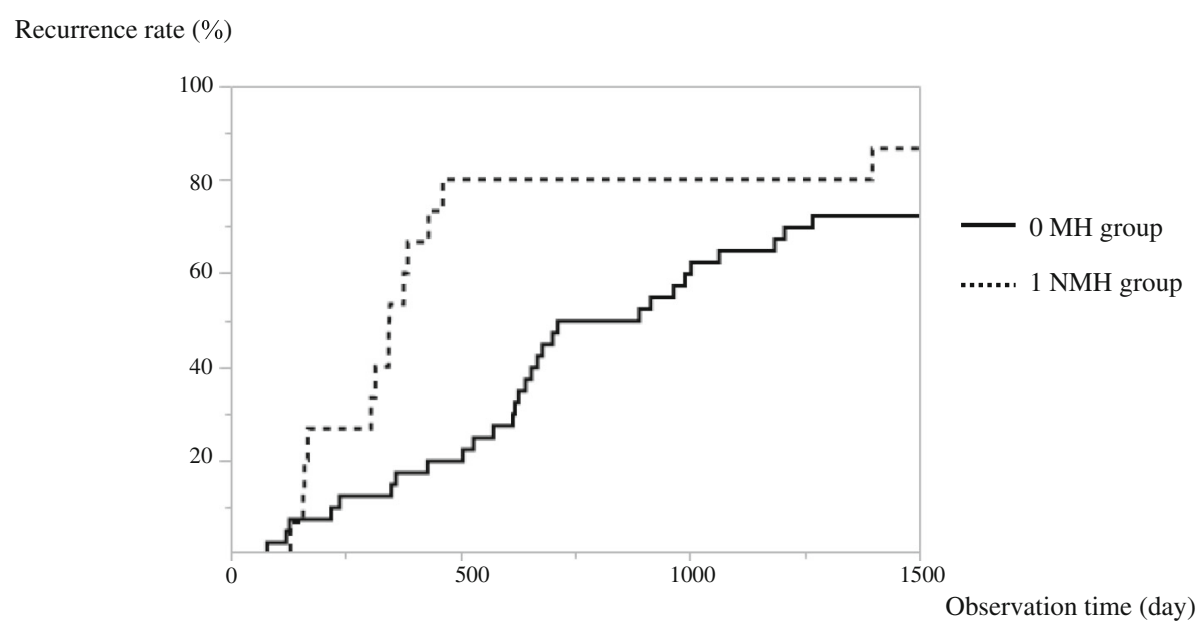

Fig. 3 Relapse rate after achieving remission 


\section{Conclusions}

TAC is effective for refractory UC, but relapse can occur after clinical induction of remission if colonoscopy shows that $\mathrm{MH}$ has not been achieved. Colonoscopy should always be performed to evaluate the mucosal response at completion of TAC. We suggest continuing TAC for long-term $\mathrm{MH}$.

\section{Abbreviations}

AZA: Azathioprin; CAl: Clinical active index; CRP: C-reactive protein; $\mathrm{MH}$ : Mucosal healing; NMH: Nonmucosal healing; TAC: Tacrolimus; PSL: Prednisolone; UC: Ulcerative colitis; UCEIS: Ulcerative colitis endoscopic index of severity

\section{Acknowledgements}

The authors thank Dr. Satoru Shimizu for the helpful discussion during the preparation of this paper.

\section{Authors' contributions}

Al and KT: study concept and design; SM, TO, and Al: data acquisition; Al: statistical analysis and drafting of the first version of the manuscript; Al, SN, and KT: critical revision and approval of the final version of the manuscript. This co-author has obtained approval for this manuscript. The author(s) read and approved the final manuscript.

\section{Funding}

The authors declare no conflicts of interest associated with this manuscript.

\section{Availability of data and materials}

The datasets during and/or analysed during the current study available from the corresponding author on reasonable request

\section{Ethics approval and consent to participate}

The study was conducted with strict adherence to the Declaration of Helsinki. The study protocol was reviewed and approved by the Ethics Review Committee of Tokyo Women's Medical University (4101). Informed consent to participate this study was obtained from all patients in writing or orally. The procedure for oral consent was approved by the ethics committee.

\section{Consent for publication}

Not applicable.

\section{Competing interests}

The authors declare no competing interests to this study.

Received: 23 October 2019 Accepted: 22 May 2020

Published online: 26 June 2020

\section{References}

1. Ungaro R, Mehandru S, Colombel JF. Ulcerative colitis. Lancet. 2017;29(389): 1756-70.

2. Harbord M, Eliakim R, Carbonnel F, et al. Third European evidence-based consensus on diagnosis and management of ulcerative colitis. Part 2: current management. J Crohn's Colitis. 2017;11:769-84.

3. Randall J, Singh B, George BD, et al. Delayed surgery for acute severe colitis is associated with increased risk of postoperative complications. Br J Surg. 2010;97(3):404-9.

4. Øresland T, Bemelman WA, D'Hoore A, et al. European evidence based consensus on surgery for ulcerative colitis. J Crohn's Colitis. 2015:9:4-25.

5. Ogata $\mathrm{H}, \mathrm{Nakamura} \mathrm{M}, \mathrm{Hibi} \mathrm{T}$, et al. A randomised dose finding study of oral tacrolimus (FK506) therapy in refractory ulcerative colitis. Gut. 2006;55:1255-62.

6. Komaki Y, Komaki F, Sakuraba A, et al. A efficacy and safety of tacrolimus therapy for active ulcerative colitis; a systematic review and meta-analysis. J Crohn's Colitis. 2016;10:484-94.

7. Frøslie KF, Jahnsen J, Vatn MH, et al. Mucosal healing in inflammatory bowel disease: results from a Norwegian population-based cohort. Gastroenterology. 2007;133:412-22.
8. Schroeder KW, Tremaine WJ, Ilstrup DM. Coated oral 5-aminosalicylic acid therapy for mildly to moderately active ulcerative colitis. A randomized study. N Engl J Med. 1987;317:1625-9.

9. Travis SP, Schnell D, Sandborn WJ, et al. Reliability and initial validation of the ulcerative colitis endoscopic index of severity. Gastroenterology. 2013; 145:987-95.

10. Lichtiger S, Present DH, Hanauer S, et al. Cyclosporine in severe ulcerative colitis refractory to steroid therapy. N Engl J Med. 1994;330:1841-5.

11. Bertani L, Bodini G, Francesco C, et al. Corticosteroid treatment at diagnosis: an analysis of relapses, disease extension, and colectomy rate in ulcerative colitis. Digest Dis Sci. 2019); PMID: 31754992. https://doi.org/10.1007/s10620019-05959-y.

12. Colombel JF, Rutgeerts P, Sandborn WJ, et al. Early mucosal healing with infliximab is associated with improved long-term clinical outcomes in ulcerative colitis. Gastroenterology. 2011;141:1194-201.

13. Truelove SC, Jewell DP. Intensive intravenous regimen for severe attacks of ulcerative colitis. Lancet. 1974;1:1067-70.

14. Testa A, Castiglione F, Colombo GL, et al. Adherence in ulcerative colitis: an overview. Patient Prefer Adherence. 2017;22:297-303.

15. Robinson A. Review article: improving adherence to medication in patients with inflammatory bowel disease. Aliment Pharmacol Ther. 2008;27:9-14.

16. Faubion WA Jr, Loftus EV Jr, Sandborn WJ, et al. The natural history of corticosteroid therapy for inflammatory bowel disease: a population-based study. Gastroenterology. 2001;121:255-60.

17. Khan N, Abbas A, Balart L, et al. Prevalence of corticosteroids use and disease course after initial steroid exposure in ulcerative colitis. Dig Dis Sci. 2013:58:2963-9.

18. Khan NH, Almukhtar RM, Abbas AM, et al. Early corticosteroids requirement after the diagnosis of ulcerative colitis diagnosis can predict a more severe long term course of the disease - a nationwide study of 1035 patients. Aliment Pharmacol Ther. 2014:40:374-81.

19. Buchman AL. Side effects of corticosteroid therapy. J Clin Gastroenterol. 2001:33:289-94.

20. Eugene C. Ulcerative colitis practice guidelines in adults. Clin Res Hepatol Gastroenterol. 2012:36:107-9.

21. Miyoshi J, Iwao Y, Hibi T, et al. Mucosal healing with oral tacrolimus is associated with favorable medium- and long-term prognosis in steroidrefractory/dependent ulcerative colitis patients. J Crohns Colitis. 2013 Dec; 7(12):609-14.

22. Guthrie E, Jackson J, Creed F, et al. Psychological disorder and severity of inflammatory bowel disease predict health-related quality of life in ulcerative colitis and Crohn's disease. Am J Gastroenterol. 2002;97:1994-9.

23. Leong RW, Lee YT, Sung JJ, et al. Quality of life in Chinese patients with inflammatory bowel disease: validation of the Chinese translation of the inflammatory bowel disease questionnaire. Aliment Pharmacol Ther. 2003; 17:711-8.

24. Flechner SM, Kobashigawa J, Klintmalm G. Calcineurin inhibitor-sparing regimens in solid organ transplantation: focus on improving renal function and nephrotoxicity. Clin Transplantation. 2008;22(1):1-15.

25. Baumgart DC, Pintoffl JP, Dignass AU, et al. Tacrolimus is safe and effective in patients with severe steroid-refractory or steroid-dependent inflammatory bowel disease a long-term follow-up. Am J Gastroenterol. 2006;101:1048-56.

26. Li J, Zhao X, Zhang $H$, et al. Systematic review with meta-analysis: fecal calprotectin as a surrogate marker for predicting relapse in adults with ulcerative colitis. Mediat Inflamm. 2019;2019:2136501. https://doi.org/10. 1155/2019/2136501 eCollection 2019

\section{Publisher's Note}

Springer Nature remains neutral with regard to jurisdictional claims in published maps and institutional affiliations. 